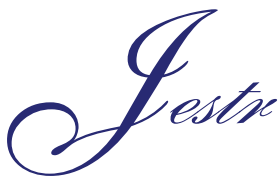

Research Article

\title{
An Investigation To The Recycling Of Spent Engine Oil
}

\author{
S. O. Ogbeide ${ }^{*}$ \\ Department Of Mechanical Engineering,Ambrose Alli University, P.M.B 14, Ekpoma, Edo State, Nigeria.
}

Received 22 June 2009; Revised 2 December 2009; Accepted 24 February 2010

\begin{abstract}
This paper describes an investigation carried out to study the recycling of spent engine oil as a result of indiscriminate disposal of the spent engine oil into the surrounding which has contributed immensely to the level of environmental pollution in our society and nation at large. This paper identify a unique method by which the spent oil is adequately recycled for reuse, the cost of recycling is relatively low compared from its production from crude oil as the numbers of purification stages are reduced. From the research carried out it was discovered that when 25 liters of spent oil was recycled appropriately, 10 liters of lubricating oil was obtained from the process whereas 220 liters of crude oil would be required to produce the same 10 liters of oil.
\end{abstract}

Keywords: Recycling, Spent oil, Environmental pollution, Crude oil, Purification.

\section{Introduction}

A lubricant (engine oil) can be defined as an oil products that separates the metal parts of an engine, reduce friction and keep it clean. Lubricant deals with the application of lubricating oil to machine [1]. Lubricants were at one time exclusively animal or vegetable oils of fats, but modern requirement in both nature and volume have petroleum as the main source of supply, lubricating oil can be produced by modern method of refining from most crude and they range from thin easily flowing spindle oils to tank cylinder oils [2].

The lubrication system of a engine is intended to avoid the increase of wear, overheating and seizure of rubbing surfaces to reduce the expenditure of indicated power on overcoming mechanical losses in the engine and also to remove wear products of a machine [3].

There are four major types of lubricant, namely - liquid, solid,

Table 1.0 Composition of mineral base oil

\begin{tabular}{lccccc}
\hline CHARACTERISTIC & $\mathbf{1 0 0 N}$ & $\mathbf{1 5 0 N}$ & $\mathbf{2 5 0 N}$ & $\mathbf{5 0 0 N}$ & $\mathbf{B S}$ \\
\hline Kinetic Viscosity (cst) & $3.9-4.3$ & $4.9-5.5$ & $6.9-7.7$ & $108-120$ & $305-325$ \\
Viscosity Index & 95 & 95 & 95 & 95 & 95 \\
Flash Point $\left({ }^{\circ} \mathrm{C}\right)$ & 193 & 204 & 210 & 221 & 226 \\
Fire Point $\left({ }^{\circ} \mathrm{C}\right)$ & 198 & 210 & 217 & 236 & 234 \\
Pour Point $\left({ }^{\circ} \mathrm{C}\right)$ & -9 & -9 & -9 & -9 & -9 \\
& Clear & Clear & Clear & Clear & Clear \\
Appearance & and & and & and & and & and \\
& Bright & Bright & Bright & Bright & Bright \\
Water content & Nil & Nil & Nil & Nil & Nil \\
\hline
\end{tabular}

*E-mail address: sammyogbes@yahoo.com

ISSN: 1791-2377 (C) 2010 Kavala Institute of Technology. All rights reserved. gaseous and plastics Lubricant, example of lubricants include oil, grease, air and graphite. Liquid and plastics lubricant are the most commonly used lubricant in industries because they are inexpensive, easily applied and good coolants while Gaseous and Solid lubricant are recommended only in some special application.

In view of the problem encountered, lubricating oil is designed to impact varieties of properties and to protect engine in so many ways. Lubricating oil is highly specialized product carefully developed to perform many essential functions among which are the following. Permit easy starting of engine, reduced friction, protecting machine against rust and corrosion, lubricating of engine parts etc [4].

\section{Objectives of the Paper}

The objectives of this paper are to:

1 highlight the sources and collection of spent engine oil

2 investigate a better and efficient way of recycling spent engine oil.

3 determine the level of cleanliness for re-use of treated oil.

\subsection{Composition of Engine Oil}

The most important consideration in engine oil is the reduction of friction and control of wears [5] where viscosity is the primary factor performance which was obtained by blending base stock or base oil with various compositions of various additives. So achiev- 
ing the right viscosity relies on selecting the right base stocks and blending item with performance additives to enhance functional performance with the advancement in refinery technologies specifically in lube processing, a sophisticated refining technique e.g. Hydro treating/hydro cracking have been introduced to convert the undesirable components of the base stocks. United State Environmental Protection Agency reported that, the base stocks used in the formulation of this engine oil are either of mineral (petroleum) or synthetic origin.

Mineral base oil are those products obtained from refining petroleum crude. While synthetic on the other hand is those products made from petroleum or vegetable feed stock and are often "tailor made" for specific application. The table below shows the physical composition of mineral based oil.

\subsection{Classification of Engine Oil}

Engine oil is normally specified in terms of their performance and viscosity grade [6]. Table 1.1 shows the engine oil viscosity classifications, three types of automotive lubricants have been defined and classified by the Society of Automotive Engineers (SAE) America:

i Crankcase oil

ii Transmission and axle lubricant

iii Fluids for hydraulic torque converters and fluid coupling

Table 1.1 Engine oil viscosity classifications

\begin{tabular}{ccccc}
\hline $\begin{array}{c}\text { SAE } \\
\text { Viscosity } \\
\text { Grade }\end{array}$ & $\begin{array}{c}\text { Viscosity at } \\
\text { temperature }\end{array}$ & $\begin{array}{c}\text { Borderline } \\
\text { pumping } \\
\text { temperature }\end{array}$ & $\begin{array}{c}\text { Viscosity } \\
\text { (ASTM d-45 cSt }\end{array}$ \\
& $\begin{array}{c}\text { cp C } \\
\text { maximum }\end{array}$ & $\begin{array}{c}\mathbf{0}^{\mathbf{C}} \\
\text { maximum }\end{array}$ & Maximum & Minimum \\
\hline 0w & $3500 @-30$ & -35 & 3.8 & $<3.3$ \\
5w & $3500 @-25$ & -30 & 3.8 & $<2.5$ \\
10w & $3500 @-20$ & -25 & 4.1 & $<3.5$ \\
15w & $3500 @-15$ & -20 & 5.6 & $<4.9$ \\
20w & $4500 @-10$ & -15 & 5.6 & $<4.6$ \\
25w & $6000 @-5$ & -10 & 9.3 & $<8.5$ \\
\hline
\end{tabular}

\subsection{Source and Collection of Spent Engine Oil}

Essentially, the source of used oil varies with the point of use and the role the virgin oil perform [7]. The table below shows the classification of spent engine oil and their source.

\section{Methodology}

\section{Recycling And Its Mechanism}

According to United State Environmental Protection Agency, recycling is the process of generating used material substances so that it can be used again. The recycling of used engine oil has to do with the mechanism and processes involved in removing the
Table 1.2 Classification of spent engine oil and their source

\begin{tabular}{|c|c|c|}
\hline Classes of waste & characteristics & $\begin{array}{c}\text { Probable source } \\
\text { point }\end{array}$ \\
\hline Aqueous waste & $\begin{array}{c}\text { Waste water containing oil } \\
\text { and more highly contami- } \\
\text { nated waste }\end{array}$ & $\begin{array}{l}\text { Refineries and } \\
\text { petrochemical } \\
\text { facilities, oil stor- } \\
\text { age installation, } \\
\text { vehicles or car } \\
\text { wash park }\end{array}$ \\
\hline Spent motor oil & $\begin{array}{l}\text { Contains contaminants } \\
\text { which are volatile (water } \\
\text { and fuel) soluble (oil } \\
\text { additives) and insoluble } \\
\text { (carbon particles), metal } \\
\text { oxides including lead } \\
\text { oxide together with a large } \\
\text { number of other trace } \\
\text { metal, and detergent }\end{array}$ & $\begin{array}{l}\text { Garages, commer- } \\
\text { cial transport un- } \\
\text { dertakings, service } \\
\text { stations, industrial } \\
\text { sites }\end{array}$ \\
\hline Spent oil emulsion & $\begin{array}{c}\text { Mainly water soluble cut- } \\
\text { ting oil, wastes containing } \\
\text { dispersed mineral oils in } \\
\text { water, soap type emulsifi- } \\
\text { ers, lube oil additives and } \\
\text { other contaminants like } \\
\text { tramp oil }\end{array}$ & $\begin{array}{l}\text { Metal working } \\
\text { industries, machine } \\
\text { shops, manufactur- } \\
\text { ing industrial engi- } \\
\text { neering activities }\end{array}$ \\
\hline $\begin{array}{l}\text { Non-emulsified oil } \\
\text { mixtures }\end{array}$ & $\begin{array}{l}\text { Mainly mineral oil waste } \\
\text { containing } 10 \%-90 \% \text { oil, } \\
\text { water, oxidized lubricant } \\
\text { materials, sediment metal } \\
\text { particles and tramp oils }\end{array}$ & $\begin{array}{l}\text { Metal working } \\
\text { industries, energy } \\
\text { sectors, manufac- } \\
\text { turing industries }\end{array}$ \\
\hline
\end{tabular}

impurities in the used oil and bringing it to the initial state. Engine oil is used up when there's no function of additive again [8].

The used oil is dark in colour due to carbon from wears. The acid present maintains the colour of the engine oil, but in used oil, the acid is weakened by the neutralization of a base. The most popular physical methods include setting, centrifugation, filtration, distillation and scrubbing with water to remove watersoluble acids.

The additive are incorporated into the recycled engine oil and sometimes mixed with fresh oil [9].

The recycling processes are the various purification that is used for the treatment of spent engine oil such that it can be used again. Research shows that various methods have been used for the purification of spent engine oil, but this research investigates the use of Solvent extraction using Sulphuric acid and activated carbon.

The choice of any method determines the level of cleanliness for re-use of the treated oil.

\subsection{Equipments and Reagents}

\section{Equipments.}

The basic equipment needed for the experiments are Beaker, Conical flask, Bunsen burner, Burette, Pipette, Thermometer, Cleveland open cup tester, Viscometer, Refractometer, Test jar, oven, Sieving machine, Test flame applicator, Litmus paper, Magnetic stirrer. 


\section{Reagents}

The reagents and its preparation to be used are dictated by the purification techniques adopted because the reagent varies from one recycling process to another. The reagent used is stated in the procedure.

\subsection{Solvent Extraction Using Sulphuric Acid and Activated Carbon}

\section{Experimental Reagent}

The basic reagents needed for the experiment include:

Activated carbon:- It is use to remove a wide variety of contaminants from the spent engine oil. It is the most frequently used for organic compounds.

Carbon-tetra chloride:- It is a synthetic chemical compound, it is clear, colorless liquid. It forms homogenous mixture with the spent engine oil and it use for testing for the iron content of the treated oil.

Base Stock:- This is the base fluid, usually a refined petroleum fraction or a selected synthetic material, into which additives are blended to produce finished lubricants.

Sulphuric Acid

Titration Solvent (as in acid clay method).

Titrant (as acid clay method).

Indicator: It is use to get the end point of the titration process.

\subsection{Recycling Process}

The sample of spent engine oil is mixed with $70 \%$ concentration of Sulphric acid in the ratio $10 \mathrm{ml}$ to $1 \mathrm{ml}$ and then heated to $60^{\circ} \mathrm{C}$ for one hour, and was allowed to settle for six (6) hours so as to enable the insoluble mater and water remain to settle at the bottom of the beaker. The treated oil is decanted and sludge formed removed from the beaker.

The treated oil is then contracted with activated carbon, and treated at $200^{\circ} \mathrm{C}-250^{\circ} \mathrm{C}$ for $2-3$ hours. The treated oil is filtered and allowed to cool. After which, the treated oil is analyzed.

\subsection{Analysis Of Samples}

\section{Test for Flash point}

A clean Cleveland open cup tester was filled with the sample oil to the meniscus line, excess oil is removed before the test proceeds. The cup positioned on the Bunsen burner with thermometer inserted vertically into the sample oil and held vertical with the thermometer holder. The bubbles present on the surface on the sample oil during heating must be get off with the aid of stirrer.

The test flame was lighted and the burner switched on, set to a minimum value for approximately value for approximately 15 seconds. The heater is lowered to half the maximum value. When the sample is approximately $56 \%$ below the anticipated flash point, the heat is decreased on the third setting.

The test flame applicator is passed across the center of the cup with smooth continuous motion. The time consume in passing the test flame across the cup in each cast should be one second.
When a flash appears at any point on the surface of the oil, the temperature at that point must be noted as the flash point. Heating is continued at one-third setting number and the applicator continually moved across the center of the oil. When the oil ignited and continues to burn for at least five (5) seconds, the thermometer reading was noted at that time. The test is then repeated.

\section{Test for Viscosity}

A clean dry viscometer tube is selected which have a flow time above 200 seconds for the fluid to be tested.

The sample is filtered through a sintered glass that eliminates dust and other solid materials in the liquid. The viscometer is charged with the sample by inverting the tubes thinner area into the liquid sample and suction is applied through the thicker area with a vacuum machine. The sample is then drawn up to the upper timing work of the inverted viscometers. Then the instrument is turned to its normal vertical position.

The viscometer is placed into the holder and inverted into the constant temperature bath maintained at $40^{\circ} \mathrm{C}$ and depending on which temperature of the sample viscosity is to be determined. 10 minutes was allowed for the sample to come to the bath temperature and after 15 minutes it reached $100^{\circ} \mathrm{C}$.

The efflux time is obtained by timing the flow of the fluid samples as it flow freely from upper meniscus mark to the lower meniscus mark. The test is repeated and the kinematics viscosity was calculated by multiplying the efflux time by the viscometer constant (it must be checked on the viscometer constant table).

\section{Total Base Number}

This test involves titrating a sample of engine oil dissolved in a mixture of titration solvent (chlorobenzene and glacial acetic acid) with a titrant (perchloric acid in glacial acetic).

The engine oil sample to be tested was weighed into a beaker; titration solvent was added in the ratio $2 \mathrm{~g}$ to $100 \mathrm{ml}$ and shake to allow mixing of the sample engine oil with the solvent. Then the titrant is titrated with $0.1 \mathrm{~N}$ per chloric acid in glacial acetic acid against the solvent and for visual determination, two drops of para Napthal benzene indicator is added to the titrant before titration begins. The orange colour changes to green or brown green at end point of titration.

A blank titrant is then prepared by adding $10 \mathrm{ml}$ of titration solvent into a beaker without any sample and then titrated.

The total base number (TBN) can then be calculated using the formula

$$
\mathrm{TNB}=\frac{\left(\mathrm{V}_{\mathrm{s} 2}-\mathrm{V}_{\mathrm{s}}\right) \times 56.1 \times \mathrm{N}}{\mathrm{W}_{\mathrm{s}}}(\mathrm{mgKOH} / \mathrm{g})
$$

Where

$\mathrm{V}_{\mathrm{s} 2}=$ volume of titrant used for titrating sample of engine oil

$\mathrm{V}_{\mathrm{s}}=$ volume of titrant used for titrating blank

$\mathrm{N}=$ normality of the titrant $=0.0641$

$\mathrm{W}_{\mathrm{s}}=$ weight of sample taken for titration

\section{Test Pour Point}

The sample engine oil is placed in the glass container and cooled by means of the cooling bath, ice and water is used down to $50^{\circ} \mathrm{F}$ $\left(10^{\circ} \mathrm{C}\right)$; crushed ice and salt down to $10^{\circ} \mathrm{F}\left(-12^{\circ} \mathrm{C}\right)$; ice calcium 
chloride down to $15^{\circ} \mathrm{F}\left(-26^{\circ} \mathrm{C}\right)$, solid carbon dioxide and petrol to $70^{\circ} \mathrm{F}\left(-57^{\circ} \mathrm{C}\right)$.

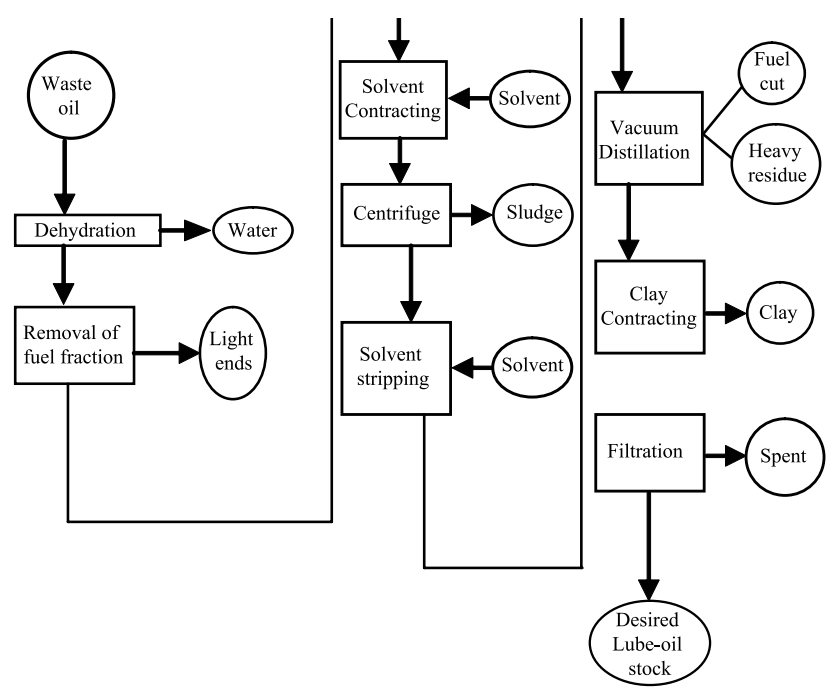

Figure 1.0 Solvent treatment for recycling spent engine oil.

The oil is then poured into the test jar to a height of not less than 2 in not more than $2 \frac{1 / 4}{4}$ inches. The pour point of engine oil is the lowest temperature at which it will pour without disturbance under standard conditioned when it was chilled.

\subsection{Iron Content}

The sample of spent engine oil was dissolved in carbon tetra chloride in the ratio of $1 \mathrm{ml}$ to $2 \mathrm{ml}$ to form a homogenous mixture and then the atomic absorption spectrometer (A.A.S) is turned on and allow to run for 10 minutes, standard solution of iron in turn is aspirated into the aspirator chamber of the A.A.S to stabilize concentration reading. The sample is aspirated into the aspirator chamber to obtain iron concentration in the sample and reading noted. The above experiment was repeated for five (5) runs and determine at 30 minutes interval.

\section{Results}

From the research carried out it was discovered that when 25 liters of spent oil was recycled appropriately, 10 liters of lubricating oil was obtained from the process and when 50 liters of spent oil was recycled 20 liters of lubricating oil was obtained from the process whereas 220 liters of crude oil would be required to produce the same 10 liters of oil and 440 liters of crude oil would be required to produce the same 20 liters of lubricating oil.

\section{Conclusion}

The recycling process has shown from research, the possibility of obtaining good quality base oils from spent engine oils. The cost of recycling (of spent engine oil) is relatively low compared to its production from crude oil as the number of purification stage involved is reduced. the highlight of the sources and collection of spent engine oil was also indicated.

Furthermore, the by-products from the process can be converted into valuable end products for other manufacturing processes, and can possibly be market. The returns from these transactions could cover the cost of buying the necessary chemical and maintain the recycling plant and therefore make the process potentially profitable.

In recent times, many marketers of lubricant have had to import base oil to blend lube products. Although, the refinery in Kaduna produces this raw material, there are periods when the vacuum distillation units breakdown and production is suspended. In the wake of such events, lubricant prices shoot up as marketers buy at higher rate from importation. If only many of these companies can invest in settling up plants that would recycle used oil, it is believe that the scarcity of base oils would be reduced. Finally, the practice of recycling spent engine oil offers a lasting solution to pollution problems caused by waste oil.

\section{References}

1. Jonathan, T. 1993. Introduction to Environment Studies, 3rd Edition Saunders College Publisher, New York. 23-41.

2. Billet, M. 1999. Institute Lubrication. Pergamon Limited, London. Pp 234-239.

3. Cock, V. R. 1998. Laboratory Handbook for Mineral Oil and Organic Oil Analysis. Academy Press, London. 111-113.

4. Idumeh, J. 2000. Lubecon Laboratory Handbook for Engine Oil Analysis. Lubecon Blending Company, Ilorin. 3-11.

5. Jilner D. A. 1997. Method for Analysis and testing of Petroleum Related products. Journals of Materials Processing Technology. 7(4): 15-21.
6. Brussels, S. and Luxembourg, R. 2001. Recycling of used Mineral Oil. Journals of Mechanical Engineering and Processing Technology, 8(12): 67-81.

7. Aliyu, T. O. 2002. Preliminary Study on the Recycling of Used Lubrication oil. Macmillan Publisher, Nigeria. 9-14.

8. Harry, M. F. 2005. Standard Handbook of Hazardous Waste and Disposal. McGraw-hill Book Company, New York. 782-793.

9. Ademola, B and Luxembourg, M. 2001. A new Approach to Caustic treatment of Waste Lubricants, Waste Treatment and Utilization. Journals of Engineering Technology, 3(2): 43-47. 